\title{
La formación del movimiento obrero en Medina-Sidonia (1872-1900)
}

\author{
DIEGO CARO CANCELA \\ Facultad de Filosofia y Letras \\ Universidad de Cádiz
}

Una de las características fundamentales del mundo contemporáneo que inaugura la Revolución Francesa es la aparición de la sociedad de clases en la civilización occidental.

La disolución jurídica de lo que se conoce comúnmente como el Antiguo Régimen, pone fin al sistema feudal, haciendo teóricamente iguales ante la ley a unos individuos que en la realidad se agrupaban ya en dos grupos claramente diferenciados: la burguesía, formada por los propietarios de los medios de producción, dueña del poder políti$\mathrm{co}, \mathrm{y}$ los trabajadores, personas que vendían su fuerza de trabajo a los primeros, a cambio de un salario. Pero clase obrera y movimiento obrero no aparecen a la par. Sólo cuando estos obreros, 1) se dan cuenta de que tienen una identidad de intereses, 2) adquieren una conciencia de clase enfrentada a la burguesía, aceptando el antagonismo como algo intrínseco a las relaciones de producción, y 3) deciden desarrollar formas de organización política y laboral, es cuando podemos decir que nace el movimiento obrero moderno (1).

Frente a la nueva sociedad que se consolida en Francia durante la Revolución, en un "ciclo revolucionario" que se inicia "desde abajo" por el pacto entre la burguesía y el campesinado frente a la aristocracia, en España se impone el llamado "modelo prusiano", una "revolución burguesa" concedida "desde arriba" por un compromiso tácito

(1) TUÑON DE LARA, Manuel: Claves de Historia Social. Barcelona-1982, p. 17. 
entre la nobleza y la burguesía, en detrimento de campesinos y jornaleros (2).

De esta manera, las sucesivas desamortizaciones, la desvinculación de los mayorazgos y la abolición de los señorios, entre otras medidas, impusieron las relaciones de producción burguesas en el mundo rural, favoreciendo a una limitada oligarquía de terratenientes, transformando al "señor feudal" en "señorito", según la acertada terminología que ha hecho ya clásica Antonio Miguel Bernal (3).

Pero este tránsito del Antiguo al Nuevo Régimen burgués no se hizo sin problemas, sobre todo en Andalucía, donde distintos pleitos señoriales, siempre resueltos a favor de los propietarios nobles, provocaron las primeras protestas en el campesinado, al exigir una serie significativa de pueblos, el uso y disfrute de dehesas y fincas que entendian estaban usurpadas por las principales familias de la aristocracia de la zona. En estas primeras protestas populares, los concejos municipales de distintos Ayuntamiento gaditanos jugaron un papel fundamental. Fueron los casos - por citar algunos- de Bornos y Alcalá de los Gazules, contra el duque de Medinaceli; de Tarifa, donde se produjeron varios intentos de ocupación de una de las dehesas señoriales; y de Espera, que tiene que renunciar al final al pleito planteado, por la falta de fondos del Ayuntamiento. En este contexto, caso distinto pudo ser el de Medina Sidonia, porque si bien estaba bajo el dominio señorial del duque, el Ayuntamiento era el mayor hacendado del lugar, por la gran cantidad de tierras de propios que poseía: 17.756 fanegas, según una relación municipal del año 1764 (4).

Esta circunstancia, en principio, parecía favorable a la gran cantidad de jornaleros que vivían en el pueblo, que creían tener la posibilidad de convertirse en propietarios, como una manera de romper las enormes desigualdades que ya se advertían en la nueva sociedad burguesa. Así lo entendía el Gobierno liberal del Trienio cuando en 1821

(2) La polémica sobre este concepto en: PEREZ GARZON, Juan Sisinio: "La revolución burguesa en España: los inicios de un debate científico, 1966-1979" en VV.AA.: Historiografía española contemporánea. Madrid, 1980, pp. 91-138; GIL NOVALEZ, Alberto (ed): La revolución burguesa en España. Madrid, 1985; MALUQUER DE MOTES, Jordi: "La revolución burguesa y el modelo liberal en España", capítulo I de El socialismo en España, 1833-1868. Barcelona, 1977, pp. 31-96.

(3) BERNAL, Antonio M.: La lucha por la tierra en la crisis del Antiguo Régimen. Madrid, 1979. Capítulo IX, pp. 329-380.

(4) RAMOS ROMERO, Marcos: Medina Sidonia. Arte, Historia y Urbanismo Cádiz, 1981, p. 208. 
decretaba el reparto en Medina, de un tercio de todas las tierras dè propios, una operación que anulaba al poco tiempo el gobierno absolutista de Fernando VII.

Con la monarquía liberal de Isabel II, se vuelve a retomar el proceso. La Ley de Devolución de 18 de mayo de 1837 obligaba a los Ayuntamientos a devolver, a quienes les habían tocado en suerte, las tierras repartidas en el Trienio.

En este ambiente, hay que situar las dos "exposiciones" que este mismo año elevaban a la Diputación Provincial un "considerable número de braceros" de Medina, solicitando la continuación de la distribución de los bienes de propios. Unas peticiones que culminaban en marzo de 1841, cuando el Ayuntamiento asidonense y el organismo provincial llegaban a un acuerdo, que contemplaba, en uno de sus apartados, "un reparto general de todas las tierras de labor y pastos entre los vecinos que las pidieren", respetando las operaciones anteriores. Sin embargo, este proyecto de 1841 también quedaba sin efecto, al proponer la propia Diputación otro distinto, que se quedaba en suspenso en la Década Moderada (1844-1854) (5).

Mientras tanto, la desamortización eclesiástica de Mendizábal, sólo servía para incrementar las propiedades de una burguesía absentista, que, poco a poco, también se iba apoderando de las suertes anteriormente repartidas entre los braceros.

Con el Bienio Progresista (1854-1856) volvía la preocupación por el reparto, sobre todo después del motín que padecía el pueblo en la noche y la madrugada del 15 de agosto de 1854. Así, a finales de este mismo mes, el 29 de agosto, se conocían en el Pleno del Ayuntamiento distintas solicitudes de tierra de braceros y pequeños propietarios que inmediatamente son atendidas, entendemos que para apaciguar los ánimos. De todas, resultaban significativas las tres fanegas y media concedidas a José Ramón Fernández, que había recibido la misma cantidad en 1841, que "roturó con el sudor de su frente", hasta que se la quitaron con la subasta de los terrenos a la que pertenecía (6).

Además, en esta misma sesión, y para dar a entender una continuidad en el proceso, el Ayuntamiento progresista recién formado acordaba iniciar las operaciones para el reparto provisional de todos los terrenos de labor de los propios de la ciudad, en suertes de cuatro

(5) Sobre estos repartos en Medina: RAMOS ROMERO, Marcos: op. cit. pp. 214-219.

(6) Archivo Municipal de Medina Sidonia (en adelante AMMS). Actas Capitulares (29-VII-1854). 
fanegas entre braceros y yunteros, decidiendo, también, practicar un deslinde general del término, "con el objeto de que vuelvan al común de estos vecinos los terrenos que se encuentran usurpados y puedan entrar en el reparto general de dominio útil" (7).

Ya por entonces, con motivo del repartimiento, la Corporación municipal asidonense identificaba a "cuatro o cinco vecinos poderosos" que acaparaban la subasta de los propios del Ayuntamiento, que serían repartidos entre los jornaleros, mientras que se dejaban para aquellos "vecinos ricos" las dehesas de pastos (8).

Pero si estos repartos apenas si paliaron el problema de la tierra en Medina, la desamortización civil de Madoz volvía a dejar intacta la estructura de la propiedad existente, al pasar a un reducido grupo de burgueses las dehesas de propios y las tierras del común, baldios y arbitrios que subsistian y los bienes propiedad de la instituciones benéficas y de instrucción pública que quedaban por subastar. $\mathrm{Y}$ es que, como bien escribe Marcos Ramos, si los repartos beneficiaron temporalmente a braceros y yunteros, los bienes vendidos en las distintas desamortizaciones fueron para los "vecinos ricos o los avispados hombres de negocios" (9).

Con la Restauración alfonsina, en el último tercio del siglo XIX, todos los indicios apuntan a un incremento del sistema latifundista, por el abandono o la venta de las parcelas que se le habían entregado a los jornaleros para su explotación directa. Así lo reconocía un informe sobre la situación de los obreros agrícolas realizado en 1902 por el Ayuntamiento, en el que se escribía que "más de 10.000 hectáreas de terreno de propios se repartieron en pequeñas parcelas entre los vecinos de esta ciudad en 1855 y sucedió que muy pocos conservaron las tierras y que la inmensa mayoría de los agraciados la enagenaron de seguida" (10). Por esta razón, era explicable que cuando se realiza el catastro de la riqueza rústica en 1930, 41 fincas de más de 250 hectáreas ocupaban cerca de la mitad del término municipal de Medina, el 42,43 por ciento de las 53.067 hectáreas catastradas (11).

(7) Ibidem.

(8) AMMS. Actas Capitulares (en adelante AC) (22-IX-1854).

(9) RAMOS ROMERO, Marcos: op. cit. p. 222.

(10) AMMS. Caja ne 530. Estadística. Relación sumaria. 1747-1968. Información acerca de los obreros agrícolas en las Provincias de Andalucía y Extremadura. Ayuntamiento de Medina. 1902. Las respuestas al cuestionario que envia el Gobierno se reproducen con bastante exactitud en el "Diario de Cádiz" del 3 de septiembre de 1902 (en adelante: Informe...)

(11) CARRION, Pascual: Los latifundios en España. Barcelona, 1975 (2 edición ampliada), pp. 237-238. 
La consecuencia más inmediata de este reparto tan desigual de là tierra era un descenso de la población de Medina, en la segunda mitad del XIX, por la constante emigración de jornaleros hacia otras poblaciones, en donde se establecían de forma temporal o definitiva en busca de trabajo. Los 12.858 habitantes del censo de 1860 se habían reducido a 11.040 al comenzar el nuevo siglo (12), como ya había advertido en 1875 Joaquín María Enrile, en las notas que insertaba en la "Historia de la ciudad de Medina-Sidonia" del vicario Martínez (13).

Estos trabajadores agrícolas eran 3.120 en 1881 (14), más de la cuarta parte de la población total del pueblo, lo que representaba el porcentaje más alto de toda la provincia de Cádiz, después de Castellar.

Sin industrialización, como ocurría en el resto de Andalucía, y con la propiedad de la tierra como el principal elemento definidor del status social, lo que caracterizaba a este trabajador del campo, carente de otros recursos, era su inmediata dependencia del jornal por las faenas que realizaban. ¿Cuál era éste en el período que estudiamos?. En 1881, según los datos que recogía un ingeniero agrónomo para el conjunto de la provincia, el salario variaba entre los 3 y 5 reales y dos gazpachos en los trabajos de cereales, y de 4 a 8 en las faenas de viña (15).

Veinte años después, en 1902, la situación apenas si había mejorado. Según el citado informe municipal, el salario en los cereales había subido a 6 reales ( 1,50 pesetas), mientras que en el trabajo a destajo, como en la siega, se ganaban 4 pesetas, "recibiendo la mitad en metálico y la otra mitad en alimentos, aunque no muy abundantes": pan, aceite, vinagre "y demás avíos para sopas y gazpachos".

Se calculaba que un bracero necesitaba diariamente en Medina 66 céntimos: 49 en pan, 7 en aceite, 4 en vinagre, sal y otros avíos para el gazpacho y sopas, y 4 céntimos en frutas, mientras que para una familia eran necesarios 7 reales en alimentos diarios. A todo ello había que añadirle las 48 pesetas al año en alquiler de casa, las 50 en ropa, las 25 en lumbre y luz y 50 en gastos extraordinarios, que hacían un total de 174,75 pesetas anuales, complementarias de las necesarias para la alimentación.

(12) RAMOS ROMERO, Marcos: op. cit. p. 43.

(13) Dice en la página 357: "La población en 1860 era de 12.858 habitantes (...) y viene disminuyendo desde entonces". Cádiz, 1875.

(14) CASTRO, Demetrio: Hambre en Andalucía. Antecedentes y circunstancias de La Mano Negra. Córdoba, 1986, p. 70.

(15) Ibídem. p. 77. 
El déficit entre el jornal del bracero - cuando trabajaba- y los gastos que tenía que afrontar era más que evidente, de aquí que el mismo informe firmado por el alcalde asidonense reconociese que la situación del obrero agrícola en 1902 no podía ser "más miserable", ni había nadie peor retribuido que él, por lo que "la solución más práctica del problema obrero" estaba "en aumentar los jornales" (16).

Los propios testimonios obreros, en la prensa anarquista de la época, confirmaban con más crudeza si cabe esta situación. Un ejemplo de lo que decimos era lo que exponía "un trabajador de Medina" en el periódico "El Corsario" de La Coruña, el 22 de octubre de 1893:

"Se principian las faenas a las tres de la
madrugada y con un gazpacho confeccionado
de ingredientes que los burgueses rechazan
para los cerdos, continúan sus trabajos
hasta las ocho de la noche que se retiran
con un jornal (pásmense) de sesenta y cinco
céntimos; con esto han de atender a las
necesidades de la familia los que todo lo
producen" (17).

La única fórmula que tenían estos jornaleros para completar los menguados ingresos del cabeza de familia era poner a trabajar, al mismo tiempo, a sus mujeres e hijos en las faenas agrícolas y ganaderas, o emplear a las hembras en el servicio doméstico, bien en casas de la burguesía local o en las de la capital de la provincia (18). Por esta razón, era frecuente el absentismo escolar en la población infantil jornalera. En el informe de 1902, que ya hemos citado, se decía que si de 6 a 7 años los hijos de los braceros de Medina faltaban muchos días a la escuela, "por carecer de ropa, por tener que acompañar a las familias en las temporadas que residen en el campo y por otras causas", a partir de los 10 años, es que dejaban las aulas definitivamente, dedicándolos sus padres "al pastoreo de los ganados o a otra ocupación análoga" (19).

(16) Informe...

(17) BREY, Gérald-MAURICE, Jacques: Historia y leyenda de Casas Vieja. Madrid, 1976 , p. 30.

(18) Informe...

(19) Ibídem.. 
No era, por tanto, extraño que el analfabetismo alcanzase en el pueblo proporciones verdaderamente alarmantes, teniendo en cuenta que las familias obreras constituían las tres cuartas partes del vecindario de Medina. Una estadística publicada en la prensa provincial, en febrero de 1868 (20), reconocía que 19.869 habitantes, de los 24.689 que formaban el partido judicial asidonense (21), no sabían leer ni escribir y 1.098 sólo leían (22), por lo que la tasa de analfabetos se situaba en el 84,9 por ciento del total de habitantes, cuando a nivel nacional este porcentaje estaba alrededor del 75 por ciento, ya de por sí uno de los más altos de Europa (23).

Y si en condiciones normales la estrechez y la miseria acompañaban al jornalero a lo largo de toda su vida, la situación alcanzaba tintes estremecedores cuando aparecían las terribles crisis de subsistencias por la falta de trabajo y la escasez de los alimentos. Estas, casi siempre coincidían con alteraciones climáticas (escasez o abundancia de lluvias), debido a la vinculación tan estrecha que había entre una agricultura tradicional, como la que se practicaba por entonces en Andalucía, y la climatología. El paro estacional se alargaba entonces hasta situaciones límites, provocando la inmediata intervención de los poderes públicos, para prevenir los desórdenes que podían provocar el hambre y la desesperación de unas familias incapaces de alimentar a todos sus miembros.

Medina-Sidonia no permaneció al margen de las grandes carestías que se extendieron por el campo andaluz en la segunda mitad del siglo XIX, especialmente las de 1857, 1868-1869 y la de 1882-1883, por citar las que más amplios efectos tuvieron (24).

El 7 de noviembre de 1868, por ejemplo, el alcalde progresista de Medina, el notario Manuel María Marín, daba cuenta a la Corporación recién constituida, que se le habían presentado "gran número de jornaleros escedentes ( $\mathrm{sic}$ ) de las labores agrícolas, pidiéndole les diese ocupación con que poder ganar su sustento" (25). Para arreglar el pro-

(20) Aparece en "La Palma de Cádiz" el 1 de febrero, y en "El Guadalete" el día siguiente.

(21) Integrado por la propia Medina, Alcalá de los Gazules y Paterna de Rivera.

(22) Se completa la lista en la "Historia de Medina" del Vicario Martínez. Cádiz, 1875 , p. 387.

(23) VILAR RAMIREZ, Juan Bautista: "La enseñanza y la ciencia," en Historia General de España y América. Tomo XVI-1 (1868-1931). Madrid, 198, p. 238.

(24) La crisis de 1857 se analiza en BERNAL, Antonio M.: op. cit. pp. 220-226 y la de 1882 en: CASTRO, Demetrio: op. cit.

(25) AMMS. AC (7-XI-1868) Caja $n^{2} 52$. 
blema, y en vista de la escasez de recursos existentes en el caudal "del común", el Ayuntamiento acordaba emprender una obra de desmonte en la Corredera, para ocupar a los parados, hasta que se gastaran los 180 escudos presupuestados.

A principios de 1870 volvía a presentarse de nuevo el problema. Esta vez, después de estar ocho días socorriendo a "la multitud de obreros" indigentes, el alcalde asidonense convocaba al Ayuntamiento a los mayores contribuyentes del término para exponerles los peligros que podían llegar, si se dejaban "sin socorro los novecientos y pico de jornaleros que reclaman dicho auxilio" (26).

Pues bien, aunque esta vez, en un principio, la Corporación aprobaba levantar un empréstito obligatorio entre los vecinos más acomodados, a pagar por contribución directa, lo difícil de la operación y la necesidad imperiosa de dinero para atender los socorros a los braceros parados, obligaban, al final, a verificar un repartimiento inmediato en el que entraban contribuyendo todo los vecinos, en proporción a su fortuna (27).

Más grave fue la crisis de 1882 , tan bien estudiada por Demetrio Castro (28), al desbordar la paciencia secular de los trabajadores, provocando motines y revueltas por toda la geografía andaluza, por la escasez de alimentos, debido a las malas cosechas de 1880 a 1882. Ya el 31 de marzo de 1882, en las Actas Capitulares del Ayuntamiento se escribía sobre la necesidad de poner remedio "a la más espantosa calamidad que con una tenacidad no conocida hasta aquí nos amenaza con el grave conflicto de no poder socorrer a los braceros". Otro escrito del alcalde al gobernador civil, fechado el 13 de mayo, daba cuenta del robo de pan a dos repartidores, uno de los cuales lo llevaba en un carro para venderlo en Chiclana (29); y dos meses después -el 27 de julio- más de 400 braceros se presentaban en el Ayuntamiento, al finalizar los trabajos agrícolas, exponiendo su "carencia absoluta de medios" para atender a sus necesidades más urgentes (30).

Esta situación apenas si variaba con el paso de los años, porque en 1902, en el informe municipal sobre la situación de los jornaleros

(26) Ibidem (15-II-1870).

(27) Ibídem (19-II-1870).

(28) CASTRO, Demetrio: op. cit., y para la provincia de Cádiz, en El movimiento obrero en la bistoria de Cádiz. Cádiz, 1988, pp. 91-126.

(29) AMMS. Policía. Correspondencia. Caja n 892. 1879-1907. Comunicación.

(30) Ibídem. 
del pueblo, el alcalde exponía que todos los años tenían unos 20 días de "calamidad pasajera", que el Ayuntamiento superaba entregando a los afectados un socorro diario de 1 a 1,25 pesetas, sin comida, o tres libras de pan a cada familia (31), unas veces por la propia Corporación municipal en solitario y, en casos más graves, contando con la colaboración de los contribuyentes.

Pero una cosa es que, ya desde mediados del siglo XIX, el campesinado andaluz estuviera claramente configurado como el estrato fundamental de la clase trabajadora de la región, y otra, que al mismo tiempo tuviera conciencia de sus propios intereses de clase, hecho que algunos han situado en la década de los ochenta de la pasada centuria (32) y que nosotros, de acuerdo con José María Jover, adelantamos a los años del "sexenio" (1868-1874). Porque, en contraste con lo que estaba ocurriendo en Cataluña, que desde el período 1840-1843 tenía uno de los sindicalismos más avanzados de Europa (33), en Andalucía, hasta que no aparecen las ideas internacionalistas a partir de 1869 , los trabajadores encauzarán sus primeras reivindicaciones sociales (abolición de los consumos y quintas o el reparto de las tierras de propios) a través de un republicanismo radical, fronterizo con el socialismo utópico, que no ocultaba su respeto por la propiedad privada, y con fórmulas más o menos ambiguas para encarar el "problema social" (34).

La falta de una conciencia de clase es perceptible en el caso de Medina-Sidonia en la reivindicación del reparto de las tierras de propios entre 1837-1855, al no plantearse como una alternativa a la emergente sociedad burguesa, sino sencillamente como una manera para mejorar unas condiciones de vida cercanas a la mera subsistencia. De aquí, también, que todas las acciones de protesta que conocemos de estos años tengan la huella de la acción espontánea o la revuelta desorganizada, con unos objetivos apenas definidos y unos participan-

(31) Informe...

(32) RODRIGUEZ AGUILERA, R.: "El nacimiento del proletariado agricola andaluz como clase social" en VV.AA.: Seis estudios sobre el proletariado andaluz (1868-1939). Córdoba, 1984, pp. 13-49.

(33) MALUQUER DE MOTES, Jordi: "Los orígenes del movimiento obrero español (1834-1874)" en VV.AA.: La era isabelina y el sexenio democrático. Tomo XXXIV de la "Historia de España" de Menéndez Pidal. Madrid, 1984, p. 782.

(34) MALUQUER DE MOTES, JORDI: El socialismo... 
tes de heterogénea procedencia social (35). Un ejemplo claro de lo que decimos es el motín que se produce en el pueblo, en la madrugada del 15 de agosto de 1854, recién inaugurado el "bienio", cuando un levantamiento de "campesinos pobres," en palabras de Marcos Ramos, (36) agita la vida de Medina, creando una situación de extrema gravedad, que las Actas Capitulares no dudan en calificar de "cedición" (37). La confusión es total sobre los móviles de una protesta que coloca a la población en estado de sitio, con las tabernas cerradas y con una "fuerza de vecinos de confianza" patrullando por las calles (38). Pues bien, si el periódico gaditano "El Nacional" habla de una asonada para derribar a los progresistas, "La Palma" cree que la causa habría que buscarla en el retraso en efectuar los repartimientos, y otra documentación sitúa los hechos en un rechazo a los "derechos de consumo" (39).

Es entre 1868 y 1875 cuando, en palabras de José María Jover, asistimos en España a la formación de una auténtica conciencia proletaria (40), con nuevos mitos para los obreros, como la huelga general o la revolución social. De todas formas, como veremos más adelante, la cristalización de esta conciencia de clase no es algo instantáneo, sino producto de un lento proceso de sedimentación que empieza con el desencanto sobre la acción política de los republicanos y termina en el apoliticismo característico de los anarquistas. Hasta el verano de 1873, el anarquismo, la Internacional y el federalismo republicano extremo, "componían un todo que no se podía separar en sus partes" (41).

(35) Sobre la formación de la conciencia de clase en el movimiento obrero: HOBSBAWM, Eric: El mundo del trabajo. Barcelona, 1987, pp. 11-50. También: RUDE, George: Revuelta popular y conciencia de clase. Barcelona, 1981. Para el caso concreto de Andalucía, las únicas páginas dedicadas al tema en BERNAL, Antonio M.: op. cit. pp. 419-456.

(36) RAMOS ROMERO, Marcos: op. cit. p. 195.

(37) AMMS. AC (16-VIII-1854). Caja ne 48.

(38) Ibídem.

(39) REY PELAYO, Manuel: Conflicto y sociedad en la provincia de Cádiz (1840-1856). Tesis de licenciatura inédita. Facultad de Filosofía y Letras. Universidad de Cádiz, 1986, p. 145.

(40) JOVER ZAMORA, José María: "Conciencia burguesa y conciencia obrera en la España contemporánea" en Política, diplomacia y bumanismo popular en la España del siglo XIX. Madrid, 1976, p. 64.

(41) MOLNAR, M-PEKMEZ, Juan: "Anarquismo rural en España y la revolución cantonalista de $1873^{\prime \prime}$ en LANDSBERGER, Henry A. (ed.): Rebelión campesina y cambio social. Barcelona, 1978, p. 222. 
En el caso concreto de Medina que estamos estudiando, la tardía llegada de las ideas internacionalistas con respecto a poblaciones vecinas, como Jerez o Cádiz, demuestran la influencia que los republicanos ejercían en el movimiento obrero local; presencia todavía más visible si tenemos en cuenta los escasos afiliados a la Federación Local de la Internacional -20- en una población activa que superaba con creces los tres mil trabajadores.

Podemos seguir los primeros pasos de este reducido núcleo de internacionalistas asidonenses, gracias a la correspondencia recogida en las Actas de los Consejos y la Comisión Federal de la Región Española de la AIT.

La primera noticia que tenemos data de principios de septiembre de 1872, cuando un tal Diego Rodríguez Vargas comunica su adhesión a la Internacional, resultado del proselitismo de un militante de Cádiz (42). El 24 del mismo mes, la dirección de la FRE conocía "el estado precario de este pueblo, víctima del fanatismo político por el que han logrado explotarle pandillas de ambiciosos por espacio de muchos años" (43), y el 4 de octubre, que se había constituido una sección con veinte trabajadores, pidiendo "estatutos, folletos y todo lo que pueda ser útil para la propaganda" (44). Y hasta Medina llegaban también los ecos de la división de la Primera Internacional entre bakunistas y marxistas, cuando uno de estos últimos, miembro de la Nueva Federación Gaditana, intenta influir en la Federación Local asidonense, entregando a uno de sus militantes un ejemplar de "La Emancipación", el órgano de prensa de la tendencia marxista en España, pero sin conseguir nada.

Plenamente asentada, la Federación Local de Medina participa como tal en el Congreso que la Sección Española de la AIT (la FRE) celebra en Córdoba a finales de 1872 y principios de 1873 , representada por el carpintero Manuel Castillo Díaz (44). Los federados del pueblo, además de pagar sus cuotas, pedían sesenta folletos de propaganda y se suscribían al "Boletín de la Federación Regional Española," que aparecía a mediados de enero de 1873. Asimismo, recibían una carta del secretario de la Comarca del Sur, en la que éste les trasladaba su pesar por la crisis de trabajo que padecían los militantes de la

(42) Actas de los consejos y Comisión Federal de la Región Española (1870-1874). Asociación Internacional de Trabajadores. Barcelona, 1969. Tomo I, p. 264.

(43) Ibídem. p. 350.

(44) ABAD DE SANTILLAN, Diego: Historia del movimiento obrero español de los orígenes a la restauración borbónica. Madrid, 1970, p. 212. 
Federación Local, censurando la conducta de los burgueses locales, lo que demostraba "la necesidad de afiliarse a nuestra Asociación, único amparo de los desheredados" (45).

Proclamada la Primera República, que los internacionalistas veían como "el último baluarte de la burguesía (...) y un desengaño completo para todos aquellos hermanos nuestros que todo lo han esperado y lo esperan de los gobiernos" (46), la primera reacción de los federados de Medina era pedir, el 19 de febrero, al Ayuntamiento el local de "Victoria baja o clase de Instrucción Pública", para celebrar en él "sesiones públicas para instrucción y propaganda de la clase obrera y para organizar sociedades obreras para beneficios de ésta" (47).

La respuesta de la recién constituida Corporación republicana la conocemos a través de las Actas de la FRE. Rechazaba la solicitud, por lo que los internacionalistas asidonenses comunicaban a su Comisión Federal que, "nosotros no esperábamos ésto de los republicanos, pero ya nos vamos convenciendo de que todos los partidos políticos son iguales" (48).

Desconocemos qué participación tendrían los anarquistas del pueblo en los confusos sucesos que terminan en la breve proclamación del cantón de Medina y la creación de un Comité de Salud Pública, a finales de julio de 1873, por los republicanos "intransigentes" de Valle Miramón y las milicias populares de trabajadores agricolas y artesanos, aunque sí sabemos que la represión gubernamental también les llegó, porque, en septiembre, la Federación Local aparecía en constitución (49).

Durante el período de clandestinidad que conoce la Internacional en España, entre 1874 y 1881 , el nombre de Medina Sidonia desaparece de las listas de Federaciones Locales que se mantenían en contacto con la dirección de la FRE, hasta que con la vuelta a la legalidad, el nacimiento de la FTRE en septiembre de 1881 y la reconstitución de la UTC, reaparece en el pueblo una sección de 46 panaderos en agosto de $1882(50)$. Tres meses después son los obreros del campo los que

(45) BREY, Gérald-MAURICE, Jacques: op. cit. p. 17.

(46) TERMES, Josep: Anarquismo y sindicalismo en España. Barcelona, 1977, p. 189.

(47) AMMS. Secretaría. Instancia. Caja $n^{2} 547$.

(48) Actas... Tomo II, p. 81.

(49) Una visión global de estos sucesos en RAMOS ROMERO, Marcos: op. cit. pp. $195-197$.

(50) KAPLAN, Temma: Origenes sociales del anarquismo en Andalucía. Barcelona, 1977, p. 144. 
se organizan y, el 26 de octubre, uno de estos federados escribía a "Là Revista Social", que las dos secciones que mantenían abierto un "Centro Obrero" habían tenido que luchar con muchísimas dificultades a causa de la "mala propaganda de los politiquillos".

Al dividirse el movimiento anarquista andaluz en una corriente extremista, que forma el grupo "Los Desheredados", y otra legalista o moderada, los militantes asidonenses se alineaban con estos últimos, censurando a "los despechados de Arcos y comparsa por su conducta" (51), protestando "contra La Mano Negra y contra toda asociación que no tenga por base la Verdad, la Justicia y la Moral" (52). Y a la vez que afirmaban el "mucho entusiasmo" que existía entre los trabajadores del campo de Medina, "en pro de los grandes principios de la Anarquía y el Colectivismo", la sección local de Agricultores también hacía público su reconocimiento al alcalde y al juez de primera instancia, porque "fieles representantes de la Ley", se habían opuesto "a que se cometiesen por el caciquismo y la Guardia Civil gran número de prisiones arbitrarias" (53).

Pero esta conducta moderada no les salvó de la gran represión que siguió a la huelga de segadores del verano de 1883 . A pesar de que los federados de Medina no habían intervenido en el conflicto, las autoridades decidían registrar su local, apoderándose del dinero y los documentos que guardaban, y ordenaban el encarcelamiento de sus cuatro principales dirigentes: el fundador de la sección, Nicolás Pérez, el secretario-corresponsal, Agustín García, el tesorero Francisco Sáenz y el joven Manuel Moreno Mendoza (54).

Según contaba éste último, casi veinte años después, el miedo provocado por la represión casi desorganizó la sociedad de agricultores, que pasó de tener cerca de 400 socios al producirse las detenciones, a apenas 50 doce días después (55).

Puestos en libertad, a los dos o tres días de salir de la cárcel, Francisco Sáenz marchaba a Valencia al Congreso que entre el 8 y el

(50) KAPLAN, Temma: Origenes sociales del anarquismo en Andalucía. Barcelona, 1977, p. 144.

(51) Arcos de la Frontera era el núcleo más significado del grupo radical de la FTRE. Vid.: KAPLAN, Temma: op. cit. pp. 159-164.

(52) "Crónica de los trabajadores de la Región española". Libro I, p. 124.

(53) Ibidem.

(54) Véase la narración que Moreno Mendoza hace de estos hechos en 1900, con motivo de una polémica con los anarquistas de "La Revista Blanca": "La Unión Obrera" (en adelante LUO) (19-VI-1900).

(55) LUO (19-VI-1900). 
10 de octubre de 1883 celebra la U'TC, resultando nombrado "secretario general" y corresponsal de la Unión, a la vez que se le confiaba a la Sociedad de Agricultores de Medina la sede del Consejo.

Sin embargo, a los pocos días, Francisco Sáenz decidía establecerse en Sevilla, argumentando que la documentación de la Unión tendría una mayor seguridad, y desde donde elaboraría "La Autonomía," el períodico-portavoz de la UTC.

Esta decisión provocaba la condena de sus compañeros de Medina, que no dudaban en descalificarlo abiertamente:

"La sección de Agricultores pone en conocimiento de toda la región, que ella no nombró a Francisco Sáenz Burgos, al Congreso regional, ni al de la Unión del Campo. Como no consta en acta de asamblea alguna" (56).

Los enfrentamientos provocan la paralización de la Unión y la celebración de un nuevo Congreso en Montellano en abril de 1884, en el que la mayoría de los delegados acuerdan retirarle el Consejo a Medina.

Estas luchas internas, que coincidian con el declive general de la FTRE, van a tener como inmediata consecuencia la desaparición de la sección de agricultores. Mientras, los panaderos seguían organizados, llegando a establecer una tahona para dar ocupación a los ocho parados que tenían, fabricando "pan de segunda clase", que cada día que pasaba tenía más pedidos, a pesar de las maniobras patronales, bajando el precio del pan para destruir la cooperativa (57).

Después de estos agitados años, desde 1884 a 1890 carecemos otra vez de noticias sobre las organizaciones obreras del pueblo, aunque se mantenía la correspondencia con los principales periódicos anarquistas del momento, a cargo de militantes aislados. En este sentido, por ejemplo, el 12 de marzo de 1891, un obrero asidonense denunciaba en "El Productor" de Barcelona, que en la población se atravesaba por una "crisis terrible", mientras que la burguesía local recurría a otros pueblos en busca de trabajadores, "por habernos negado a votar en la elección general de febrero, celebrada en nuevo régimen de sufragio universal". Y terminaba:

"A pesar de ello, continúan llamándose muy demócratas y muy republicanos los tales burgueses".

(50) "Crónica de los trabajadores de la Región española". Libro II, p. 6.

(57) BREY, Gérald-MAURICE, Jacques: op. cit. p. 30. 
Un mes después, el 19 de abril, el corresponsal en Medina del mismo periódico informaba sobre la celebración de "un gran meeting" de propaganda anarquista en la localidad, con 700 asistentes, y comunicaba también la organización de tres grupos llamados respectivamente "Luis Ling", "Parsons" y "Los hijos de padres desconocidos", los dos primeros en recuerdo de dos de las víctimas de los sucesos de Chicago, que tan gran impacto ejercieron en el movimiento obrero internacional.

Estos anarquistas celebraban el Primero de Mayo de 1981 acosados por la Guardia Civil (58), y al año siguiente, con el pretexto de los sucesos de Jerez (59), veían clausurado su Centro y la detención de varios militantes, que llegan a permanecer encarcelados dos años y medio. La situación no podía ser peor:

"La venganza de los burgueses de esta localidad llega hasta el extremo de negar el trabajo a los trabajadores anarquistas. Algunos de ellos para poder vivir se han tenido que dedicar a la caza" (60).

Pues bien, aunque entre 1893 y 1896 se mantiene constante la correspondencia que algunos militantes dirigen al periodico anarquista de La Coruña, "El Corsario" (61), la desorganización era más que evidente. Por este motivo, las nuevas sociedades que se crean en el movimiento obrero de Medina, a finales de siglo, se hacen ahora bajo la órbita del republicanismo reformista.

A finales de 1899 , desde las páginas de "La Unión Obrera" se hacía un llamamiento "A los trabajadores de Medina-Sidonia", para que formaran "las asociaciones de oficio bajo los principios de verdad, justicia y moral", siguiendo el ejemplo de poblaciones vecinas (62).

El impulsor de este proyecto para organizar a los trabajadores en el seno del republicanismo era un asidonense, ahora afincado en Jerez: Manuel Moreno Mendoza, uno de los cuatro detenidos en Medina en el verano de 1883 como miembro de la sociedad de agricultores, y ahora dedicado plenamente a los trabajos de propaganda, con

(58) En el registro a los asistentes se incautaban "hasta de las navajas más pequeñas y que son de constante uso diarion.

(59) Un análisis de estos sucesos en BREY, Gérald: "Crisis económica, anarquismo y sucesos de Jerez, 1886-1892n en Seis estudios... pp. 75-128.

(60) "El Porvenir"(9-VI-1892).

(61) BREY, Gérald-MAURICE, Jacques: op. cit. p. 30.

(62) LUO (26-XII-1899). n 17. 
repetidas excursiones por los pueblos de la comarca y desde las páginas de "La Unión Obrera". El 29 de mayo de 1900 quedaba constituida la nueva Sociedad de Agricultores de Medina, bajo la presidencia de José Delgado (63), y el 3 de julio, el secretario segundo de la misma, Juan Pérez, denunciaba desde "La Unión Obrera" los abusos del dueño del cortijo del "Vínculo", porque era el único que había acomodado a la gente, dándole "tres libras y media de pan y media panilla de aceite", con unas medidas de doble fondo, que los trabajadores habían denunciado en el Juzgado.

Este Centro de Obreros Agricultores asidonense se integraba en la Federación Regional de las Sociedades de Resistencia, creada en Villamartín a finales de septiembre de 1900 (63), y era también el que dirigía la huelga de 1900 , pidiendo un aumento de jornal, consiguiendo que se incrementara en un real diario (64) el salario de los braceros.

Hecho este rápido recorrido por las condiciones de vida y las formas organizativas de los trabajadores de Medina Sidonia en la segunda mitad del siglo XIX, ¿qué conclusiones podemos extraer? En primer lugar, podemos decir que hay una fase de protesta, típica de las revueltas del Antiguo Régimen, que alcanza su punto más álgido en el motín de la madrugada del 15 de agosto de 1854, de heterogéneos participantes y confusos objetivos y que cierra un ciclo reivindicativo de reparto la tierras de propios, frustrado al final por distintos motivos.

La llegada de las ideas internacionalistas a finales de 1872 facilita la configuración del movimiento obrero alrededor de las tesis antipolíticas del bakunismo. Pero la aparición de una conciencia de clase entre los trabajadores asidonenses no es algo instantáneo, sino producto de una lenta maduración, perceptible, tanto en la correspondencia con la Comisión Federal de la FRE como en las cartas y escritos que desde el pueblo se remiten a la prensa anarquista. El primer desencanto que provoca la actuación política de los republicanos en 1873 - sus iniciales adversarios- abre camino a una correspondencia cada vez más "clasista", con frecuentes denuncias sobre los "burgueses", sus enemigos cada vez más definidos, dando así forma a una de las claves más definitorias del movimiento obrero contemporáneo. En este contexto, la breve adhesión de los agricultores asidonenses a las

(63) LUO (10-X-1900). Sobre esta organización, vid. mi artículo: "La Federación de Trabajadores de Andalucía. Republicanismo y movimiento obrero a principios del siglo XX," en IV Congreso sobre el Andalucismo Histórico. Cádiz, 1989.

(64) Informe... 
tesis reformistas del republicanismo decimonónico, sólo puede entenderse por la crisis orgánica del anarquismo español en el tránsito de un siglo a otro. No por una presunta reconversión ideológica que en todo caso, sólo afectaba a la vanguardia del obrerismo y no a las bases del mismo, ajenas a unas disputas teóricas que les quedaban muy lejos a unos jornaleros que, en su inmensa mayoría, apenas si sabian leer o escribir y que bastante tenían con buscar el sustento diario para ellos y sus familias. 